\title{
Gambaran Kualitas Hidup Pasien dengan Keluhan Dispepsia yang Diberi Perawatan dengan Jamu (Data Registri Jamu 2014-2018)
}

\author{
The Quality of Life of Patients with Dyspepsia Treated with Jamu (Jamu \\ Registry Data 2014-2018)
}

Tri Wahyuni Lestari' ${ }^{1}$, Nita Prihartini $^{1}$, Delima $^{1}$

1) Pusat Penelitian dan Pengembangan Sumber Daya dan Pelayanan Kesehatan, Jalan Percetakan Negara No. 29 Jakarta 10560, Indonesia

Korespondensi: wahyuni_lestari29@yahoo.com

Submitted: 05 Mei 2020, Revised: 30 Juli 2020, Accepted: 11 Agustus 2020

https://doi.org/10.22435/jpppk.v4i2.3769

\begin{abstract}
Abstrak
Registri jamu merupakan sistem pencatatan pelayanan kesehatan menggunakan jamu atau herbal berbasis web yang dikembangkan oleh Balitbangkes. Artikel ini bertujuan mengetahui gambaran kualitas hidup pasien dengan keluhan dispepsia yang diberi jamu oleh dokter praktik jamu. Desain penelitian Registri Jamu yaitu potong lintang. Data dikumpulkan dari data rekam medik 186 pasien dispepsia yang berobat pada 64 dokter yang termasuk dalam jejaring dokter praktik jamu di 10 provinsi di Indonesia tahun 2014-2018. Data diekstrak dari sistem pencatatan Registri Jamu dan dianalisis secara deskriptif. Kualitas hidup dinilai menggunakan instrumen kualitas hidup 4 dimensi (8 pertanyaan) dan skala Nepean khusus dispepsia. Hasil analisis menunjukkan sebagian besar pasien dispepsia yang berobat pada dokter praktik jamu adalah perempuan, usia 45-64 tahun, pendidikan tamat perguruan tinggi, pekerjaan wiraswasta, berobat pada fasyankes klinik, berada di provinsi Jawa Tengah. Enam gejala umum dispepsia terbanyak yaitu: tidak nafsu makan, lemah/ letih, sulit tidur, nyeri ulu hati, demam, dan pucat. Kualitas hidup pasien dengan keluhan dispepsia yang diberi perawatan dengan jamu oleh dokter praktik jamu cenderung rmeningkat seiring dengan bertambahnya frekuensi waktu kunjungan.
\end{abstract}

Kata kunci: dispepsia, registri jamu, kualitas hidup

\begin{abstract}
Jamu Registry is a web-based health service recording system developed by Balitbangkes. This article aims to describe the quality of life of patients with dyspepsia treated with jamu by doctors. Research on Jamu Registry was a cross-sectional study. Data was collected from medical record of 186 dyspepsia patients treated by 64 doctors prescribing herbal medicine in their services in 10 provinces in Indonesia from 2014-2018. This data was extracted from the Jamu Registry recording system and analyzed descriptively. The quality of life was assessed using 4 dimensions (8 items) quality of life questionnaire and Nepean scale for dyspepsia. The results showed dyspepsia patients in this study were mostly female, aged 45-64 years, highly educated, worked as an entrepreneur, sought treatment at clinical health facility, located in Central Java province. The six common symptoms of dyspepsia recorded were: lack of appetite, weakness / fatigue, sleep disorders, heartburn, fever and pallor. The quality of life of patients with dyspepsia who were given jamu by the herbal medicine practitioner tended to increase along with the frequency of visit.
\end{abstract}

Keywords: dyspepsia, herbal medicine registry, quality of life 


\section{Pendahuluan}

Dispepsia merupakan kumpulan gejala seperti sensasi nyeri atau tak nyaman di perut bagian atas, rasa terbakar, mual muntah, penuh dan kembung. Terdapat berbagai mekanisme yang mungkin mendasari gejala dispepsia seperti gangguan motilitas usus, hipersensitivitas, infeksi, ataupun faktor psikososial. Gangguan dispepsia ini dapat menurunkan kualitas hidup pasien ${ }^{1}$. Dispepsia sering ditemukan pada praktik klinik dokter seharihari. Jumlahnya diperkirakan mencapai 30\% kasus dari praktik dokter umum. Sementara pada praktik dokter spesialis gastroenterologi mencapai hampir 60\% kasus. ${ }^{2}$ Data Registri Jamu tahun 2016-2018 menyebutkan dispepsia menempati diagnosis teratas, disusul diabetes melitus, hipertensi, ambeien, dan artritis. ${ }^{3}$ Lebih dari $50 \%$ pasien dispepsia fungsional berada dalam masa pengobatan sepanjang waktu, memerlukan biaya pengobatan yang tidak sedikit dan kira-kira $30 \%$ pasien mengambil libur dalam bekerja dan sekolah akibat dari kekambuhan gejala penyakit, hal ini tentu menurunkan kualitas hidup. ${ }^{2}$

Pada penelitian penilaian kualitas hidup terkait kesehatan (Health-related quality of life (HRQoL) pada pasien dispepsia fungsional di Indonesia yang bertujuan untuk mengetahui apakah terdapat kontribusi faktor klinis, psikososial, dan demografis terhadap HRQoL, memperlihatkan bahwa terdapat gangguan HRQoL yang signifikan pada pasien dispepsia fungsional ini di Indonesia. Faktor yang terkait secara signifikan dengan HRQoLyang rendah yaitu kegelisahan, depresi, bertambahnya usia, jenis kelamin perempuan, keparahan gejala yang lebih besar, dan tingkat pendidikan rendah hingga menengah. ${ }^{4}$ Salah satu usaha untuk meningkatkan kualitas hidup pasien dispepsiayaitudenganmemadukanantarapengobatan konvensional dan alternatif komplementer (CAM). Terapi CAM untuk mengatasi keluhan dispepsia semakin banyak digunakan di seluruh dunia. Hampir $50 \%$ pasien rawat jalan gastroenterologi di Kanada telah menerapkan perawatan dengan terapi suportif CAM. $^{5}$

World Health Organization (WHO) telah sepakat untuk memajukan pemanfaatan pengobatan tradisional komplementer untuk kesehatan dan wellness yang bersifat people centered dalam pelayanan kesehatan. Untuk itu perlu diwujudkan pula pelayanan kesehatan yang patient centered dan mampu menyembuhkan secara holistik (bodymind-spirit) untuk mencapai kualitas hidup yang lebih baik. ${ }^{6}$ Badan Penelitian dan Pengembangan Kesehatan (Balitbangkes) telah mengembangkan sistem pencatatan pelayanankesehatanmenggunakan jamu atau herbal berbasis web yang disebut Registri Jamu. Salah satu tujannya adalah teridentifikasinya ramuan jamu dan pelayanan kesehatan tradisional (yankestrad) lain yang digunakan oleh para dokter praktik yang menunjukkan manfaat awal, untuk selanjutnya dapat dikaji melalui uji klinis yang lebih kokoh. ${ }^{6}$ Registri jamu dilakukan dalam rangka menyediakan bukti ilmiah yang cukup untuk mengantisipasi berkembangnya penggunaan jamu oleh masyarakat dan tenaga kesehatan. Diharapkan dengan tersedianya bukti ilmiah maka pelayanan jamu/herbal dapat dimasukkan dalam pelayanan kesehatan formal. Dengan demikian, Registri Jamu mendukung integrasi jamu dalam pelayanan kesehatan. Percepatan pembuktian ilmiah dapat dilakukan dengan mempelajari data pelayanan jamu/herbal yang sudah dilakukan oleh para dokter praktik. Registri Jamu dikembangkan sejak tahun 2014 kemudian direvisi pada tahun 2016 dan 2018. ${ }^{3}$

Artikel ini bertujuan menganalisis data Registri Jamu untuk mengetahui gambaran kualitas hidup pasien dengan keluhan dispepsia yang diberi jamu oleh dokter praktik jamu.

\section{Metode}

Desain penelitian Registri Jamu adalah potong lintang non-intervensi. Lokasi penelitian bertempat di puskesmas, klinik jamu, praktik bersama, dan praktik mandiri yang termasuk dalam jejaring dokter praktik jamu. Populasi merupakan pasien dengan keluhan dispepsia pada dokter praktik jamu di Puskesmas, klinik dan praktik mandiri yang berada pada jejaring dokter di 10 provinsi, yaitu Bali, Banten, DKI Jakarta, Jambi, Jawa Barat, Jawa Tengah, Jawa Timur, Kalimantan Timur, Sulawesi Selatan, dan Sumatera Selatan. Kriteria inklusi sampel adalah pasien dispepsia yang mendapat terapi jamu dan atau dikombinasi dengan yankestrad lainnya atau obat konvensional. Kriteria eksklusi adalah pasien yang hanya mempunyai data kunjungan pertama. Data diekstrak dari database Registri Jamu pada Indonesia Registry 
Web Portal www.ina-registry.org yang dikelola oleh Pusat Penelitian dan Pengembangan Sumber Daya dan Pelayanan Kesehatan tahun 2014-2018. Registri Jamu merupakan bagian dari Registri Penyakit Indonesia. Data pasien dispepsia dianalisis secara deskriptif terhadap variabel karakteristik pasien, gejala umum, kualitas hidup umum (QoL) 8 pertanyaan versi Saintifikasi Jamu, kualitas hidup khusus dispepsia (Nepean Dyspepsia Index) yang terdiri dari 10 pertanyaan, dan tatalaksana pengobatan. Penilaian kualitas hidup dilakukan melalui wawancara pasien dengan skala 1-4 untuk setiap pertanyaan instrumen kualitas hidup umum dan skala 1-5 untuk setiap pertanyaan instrumen kualitas hidup khusus. Kualitas hidup umum dikategorikan menjadi 3 yaitu buruk (nilai 8-16), sedang (17-24), dan baik (25-32). Kualitas hidup khusus dikategorikan menjadi 3 yaitu buruk (nilai 10-23), sedang (24-37) dan baik (38-50). 7,8

Penelitian Registri Jamu telah mendapatkan persetujuan etik dari Komisi Etik Penelitian Kesehatan Badan Litbangkes No.LB.02.01/5.2/ KE.118/2014, LB.02.01/5.2/KE 412/2016 dan LB.02.01/2/KE 119/2018.

\section{Hasil}

Berikut adalah data karakteristik 186 pasien dengan keluhan dispepsia yang berobat pada jejaring dokter praktik jamu di fasyankes dari tahun 2014-2018.

Karakteristik pasien dengan keluhan dispepsia yang berobat pada dokter praktik yaitu dilihat dari jenis kelamin terbanyak yaitu perempuan $(55,9 \%)$, dari segi usia terbanyak 45-64 th $(46,2 \%)$, dari segi pendidikan terbanyak tamat SLTA $(35,5 \%)$, dari segi pekerjaan yaitu wiraswasta $(26,3 \%)$, dari segi fasyankes tempat berobat yaitu klinik $(48,4 \%)$, dari segi wilayah/ lokasi fasyankes terbanyak berada pada provinsi Jawa Tengah (57,0\%).

Enam gejala umum terbanyak yang dikeluhkan pasien dispepsia yang berobat pada jejaring dokter praktik jamu 2014-2018 yaitu: tidak nafsu makan, lemah/letih, sulit tidur, nyeri ulu hati, demam, dan pucat.

Kualitas hidup sebagian besar pasien dispepsia yang sudah mendapat terapi dari dokter praktik jamu yang semula dalam kategori sedang
Tabel 1. Karakteristik 186 Pasien Dispepsia, Registri Jamu 2014—2018

\begin{tabular}{|c|c|c|c|}
\hline No. & Karakteristik & $\mathbf{n}$ & $\%$ \\
\hline \multirow[t]{3}{*}{1} & Jenis kelamin & & \\
\hline & Laki-laki & 82 & 44.1 \\
\hline & Perempuan & 104 & 55,9 \\
\hline \multirow[t]{6}{*}{2} & Usia (tahun) & & \\
\hline & $<15$ & 4 & 2,2 \\
\hline & $15-24$ & 16 & 8,6 \\
\hline & $25-44$ & 66 & 35,5 \\
\hline & $45-64$ & 86 & 46,2 \\
\hline & $\geq 65$ & 14 & 7,5 \\
\hline \multirow[t]{7}{*}{3} & Pendidikan & & \\
\hline & Tidak sekolah & 2 & 1,1 \\
\hline & Tidak tamat SD & 12 & 6,5 \\
\hline & Tamat SD & 29 & 15,6 \\
\hline & Tamat SLTP & 18 & 9,7 \\
\hline & Tamat SLTA & 66 & 35,5 \\
\hline & Tamat Perguruan Tinggi & 59 & 31,7 \\
\hline \multirow[t]{8}{*}{4} & Pekerjaan & & \\
\hline & Tidak bekerja & 28 & 15,1 \\
\hline & Sekolah & 14 & 7,5 \\
\hline & Tentara/Polisi/PNS & 29 & 15,6 \\
\hline & Pegawai Swasta & 34 & 18,3 \\
\hline & Wiraswasta & 49 & 26,3 \\
\hline & Buruh/Petani/Nelayan & 23 & 12,4 \\
\hline & Lainnya & 9 & 4,8 \\
\hline \multirow[t]{4}{*}{5} & Jenis Fasyankes & & \\
\hline & Puskesmas & 25 & 13,4 \\
\hline & Klinik & 90 & 48,4 \\
\hline & Praktik perorangan/mandiri & 71 & 38,2 \\
\hline \multirow[t]{11}{*}{6} & Provinsi Lokasi Fasyankes & & \\
\hline & Bali & 18 & 9,7 \\
\hline & Banten & 25 & 13,4 \\
\hline & DKI Jakarta & 13 & 7,0 \\
\hline & Jambi & 2 & 1,1 \\
\hline & Jawa Barat & 12 & 6,5 \\
\hline & Jawa Tengah & 106 & 57,0 \\
\hline & Jawa Timur & 2 & 1,1 \\
\hline & Kalimantan Timur & 3 & 1,6 \\
\hline & Sulawesi Selatan & 2 & 1,1 \\
\hline & Sumatera Selatan & 3 & 1,6 \\
\hline
\end{tabular}


pada kunjungan ke-1 meningkat menjadi kategori baik pada kunjungan ke-2, ke-3, dan pada kunjungan ke-4 tidak ada lagi pasien dengan kualitas hidup buruk. Demikian pula pada skor skala Nepean.
Jumlah pasien yang menggunakan jamu saja 126 orang (67,7\%); menggunakan jamu dan obat konvensional sebanyak 31 orang (16,7\%); menggunakan jamu dan kestrad sebanyak 19 orang

Tabel 2. Kualitas Hidup (Quality of Life) 186 Pasien Dispepsia menurut Kunjungan, Registri Jamu 2014-2018

\begin{tabular}{rlrrrrrrrr}
\hline No & $\begin{array}{l}\text { Kualitas } \\
\text { hidup }\end{array}$ & \multicolumn{2}{c}{$\begin{array}{c}\text { Kunjungan 1 } \\
\text { (N=186) }\end{array}$} & \multicolumn{2}{c}{$\begin{array}{c}\text { Kunjungan 2 } \\
\text { (N=126) }\end{array}$} & $\begin{array}{c}\text { Kunjungan 3 } \\
(\mathbf{N}=\mathbf{5 7})\end{array}$ & \multicolumn{2}{c}{$\begin{array}{c}\text { Kunjungan 4 } \\
(\mathbf{N}=\mathbf{3 4})\end{array}$} \\
\cline { 2 - 11 } & $\mathbf{n}$ & $\mathbf{0}$ & $\mathbf{n}$ & $\mathbf{\%}$ & $\mathbf{n}$ & $\mathbf{\%}$ & $\mathbf{n}$ & $\mathbf{\%}$ \\
\hline 1 & Baik & 73 & 39,2 & 84 & 66,7 & 42 & 73,7 & 24 & 70,6 \\
2 & Sedang & 105 & 56,5 & 39 & 31,0 & 13 & 22,8 & 10 & 29,4 \\
3 & Buruk & 8 & 4,3 & 3 & 2,4 & 2 & 3,5 & 0 & 0 \\
\hline
\end{tabular}

Tabel 3. Kualitas Hidup Skala Nepean 90 Pasien Dispepsia menurut Kunjungan, Registri Jamu 2016-2018*

\begin{tabular}{|c|c|c|c|c|c|c|c|c|c|}
\hline \multirow[t]{2}{*}{ No } & \multirow{2}{*}{$\begin{array}{l}\text { Kualitas } \\
\text { hidup }\end{array}$} & \multicolumn{2}{|c|}{$\begin{array}{c}\text { Kunjungan } 1 \\
(\mathbf{N}=90)\end{array}$} & \multicolumn{2}{|c|}{$\begin{array}{c}\text { Kunjungan } 2 \\
(\mathbf{N}=90)\end{array}$} & \multicolumn{2}{|c|}{$\begin{array}{c}\text { Kunjungan } 3 \\
(N=48)\end{array}$} & \multicolumn{2}{|c|}{$\begin{array}{c}\text { Kunjungan } 4 \\
(\mathrm{~N}=32)\end{array}$} \\
\hline & & $\mathrm{n}$ & $\%$ & $\mathrm{n}$ & $\%$ & $\mathrm{n}$ & $\%$ & $\mathrm{n}$ & $\%$ \\
\hline 1 & Baik & 31 & 34,4 & 46 & 51,1 & 37 & 77,1 & 28 & 87,5 \\
\hline 2 & Sedang & 51 & 56,7 & 41 & 45,6 & 11 & 22,9 & 4 & 12,5 \\
\hline 3 & Buruk & 8 & 8,9 & 3 & 3,3 & 0 & 0 & 0 & 0 \\
\hline
\end{tabular}

*) Data kualitas hidup skala Nepean pada Registri Jamu 2014 tidak dianalisis karena tidak lengkap

$(10,2 \%)$; sedangkan yang menggunakan jamu, obat konvensional dan kestrad sebanyak 10 orang $(5,4 \%)$. Kestrad lain berupa akupunktur, akupresur, pijat, dan bekam.
Jenis herbal dalam ramuan yang digunakan oleh dokter yang berpartisipasi dalam penelitian ini untuk perawatan pasien dengan dispepsia sebagian besar mengandung kunyit, jahe, dan temulawak.

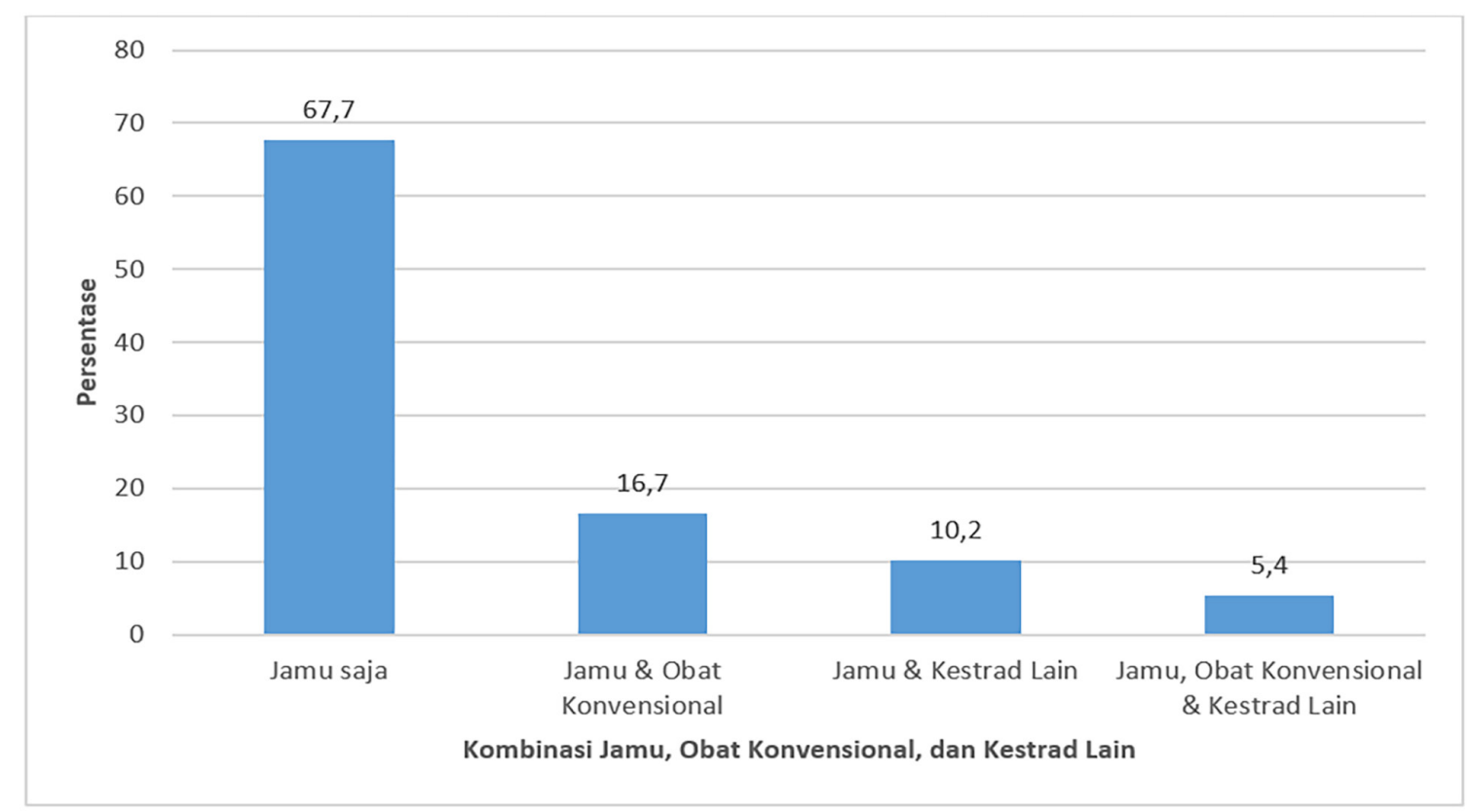

Gambar 1. Tata Laksana Pengobatan Pasien Dispepsia oleh Dokter Praktik Jamu pada Kunjungan Ke-1 


\section{Pembahasan}

Karakteristik pasien dengan keluhan dispepsia yang berobat pada dokter jamu yaitu dilihat dari jenis kelamin terbanyak yaitu perempuan $(55,9 \%)$. Hasil ini sejalan dengan penelitian mengenai karakteristik pasien dispepsia yang mengalami kekambuhan yang menyebutkan bahwa proporsi tingkat kekambuhan dispepsia fungsional tertinggi menurut jenis kelamin yaitu frekuensi sering terbanyak pada perempuan. ${ }^{2} \mathrm{Hal}$ ini dimungkinkan karena perempuan dipengaruhi oleh hormon reproduksi seperti progesteron, estradiol dan prolaktin yang pada beberapa studi dapat memengaruhi kontraktilitas otot polos dan memperlambat waktu transit gastrointestinal. ${ }^{9}$ Selain itu pola makan perempuan terutama yang sedang menjalani diet merupakan salah satu faktor penyebab kejadian dispepsia. ${ }^{10}$ Sebuah penelitian mengevaluasi diagnosis dispepsia fungsional menunjukkan bahwa kelompok terbesar usia penderita dispepsia adalah 46 hingga 60 tahun, disusul kelompok usia 31 hingga 45 tahun. Pada pasien antara usia 45 dan 60 tahun, tampak jelas bahwa gejala dispepsia umumnya disertai dengan lesi terbatas makroskopik pada mukosa lambung. ${ }^{11}$ Pertambahan usia seseorang seringkali dihubungkan dengan penurunan aktivitas olahraga rutin dan penurunan aktivitas hormonal fisiologis seseorang, Hal ini juga menyebabkan meningkatnya risiko kekambuhan dispepsia fungsional. ${ }^{2}$ Dari segi pendidikan, pasien dengan keluhan dispepsia terbanyak pada tingkat pendidikan tamat perguruan tinggi. Hal ini senada dengan penelitian lain yang menyebutkan penderita yang mempunyai pendidikan tinggi mempunyai pekerjaan yang cenderung lebih berat dibandingkan penderita dengan pendidikan menengah ke bawah. Hal ini mungkin menyebabkan stres psikologis yang lebih besar dibandingkan tingkat pendidikan yang lebih rendah. ${ }^{2}$

Enam gejala umum terbanyak yang dikeluhkan pasien dispepsia yang berobat pada jejaring dokter praktik jamu 2014-2018 yaitu: tidak nafsu makan, lemah/letih, sulit tidur, nyeri ulu hati, demam, dan pucat. Gambaran klinis dispepsia terkadang tumpang tindih dengan penyakit saluran cerna lain ataupun penyakit non-saluran cerna. Penyakit saluran cerna lain: saluran cerna atas (GERD, functional heartburn, mual idiopatik), saluran cerna bawah (irritable bowel syndrome); penyakit nonsaluran cerna; penyakit jantung seperti: iskemia, atrial fibrilasi; sindrom nyeri somatik (fibromialgia, chronic fatigue syndrome, interstitial cystitis/ bladder pain syndrome, dan overactive bladder). Meskipun dispepsia fungsional berlangsung kronis dan memengaruhi kualitas hidup, namun tak terbukti menurunkan harapan hidup. Prognosis dispepsia fungsional mungkin dipengaruhi beberapa hal; kurang tidur dan status pernikahan yang buruk memiliki prognosis negatif, sedangkan personalitas ekstrovert memiliki prognosis positif. ${ }^{1}$ Stres psikologis merupakan salah satu faktor risiko yang sering menjadi pencetus kekambuhan dispepsia, termasuk di dalamnya kecemasan, hipersensitivitas, dan neurotisme. ${ }^{2}$ Pengobatan dispepsia bertujuan untuk menghilangkan gejala, meningkatkan kualitas hidup, dan menyembuhkan penyebab. ${ }^{12}$ Penyakit ini bukan merupakan suatu penyakit yang dapat sembuh sendiri (self limited disease), sehingga upaya pengobatan untuk mengurangi frekuensi dan intensitas serangan dispepsia akut sangat diperlukan. Pengobatan farmakologis untuk pasien dispepsia fungsional belum begitu memuaskan. ${ }^{13}$ Untuk itu pengobatan konvensional sering dikomplemenkan dengan pengobatan non-konvensional atau tradisional.

Keunggulan atau keistimewaan dalam pengobatan tradisional (holistik) yaitu dalam hal melihat manusia (pasien) secara utuh yakni "bodymind-spirit", dan juga bahwa "respon diri pasien" terhadap intervensi jauh lebih penting dari pada "efek obat". Dengan demikian, respon pasien (secara holistik) harus dilihat sebagai interaksi yang utuh antara penyembuh, pasien, dan modalitas intervensi (produk). ${ }^{14}$ Oleh karena itu, Registri Jamu berbeda dengan rekam medis konvensional dalam hal detail penggunaan jamu dan kualitas hidup pasien. Dalam Registri Jamu dilakukan evaluasi kualitas hidup khusus kasus dispepsia menggunakan Nepean Dyspepsia Index selain penilaian kualitas hidup secara umum. ${ }^{8}$

Evaluasi kualitas hidup skala Nepean pada Registri Jamu dilakukan mulai 2016. Oleh karenanya hanya dilakukan evaluasi kualitas hidup skala Nepean 2016-2018. Kualitas hidup umum sebagian besar pasien dispepsia yang sudah mendapat terapi dari dokter praktik jamu yang 
semula termasuk kategori sedang pada kunjungan 1, meningkat kualitas hidupnya menjadi baik pada kunjungan selanjutnya, dan pada kunjungan ke-4 tidak ada lagi pasien dengan kualitas hidup buruk. Demikian pula pada skor skala Nepean (Tabel 3). Hal ini mengindikasikan bahwa tatalaksana terapi komplementer yang diberikan oleh jejaring dokter praktik jamu dapat meningkatkan kualitas hidup pasien dengan keluhan dispepsia. Tata laksana yang diberikan oleh jejaring dokter praktik jamu pada pasien dengan keluhan dispepsia sebagian besar terdiri atas jamu saja dan sebagian lagi kombinasi jamu dengan obat konvensional dan yankestrad lain.

Jenis herbal dalam ramuan yang digunakan oleh dokter yang berpartisipasi dalam penelitian ini untuk perawatan pasien dengan dispepsia sebagian besar mengandung kunyit, jahe, dan temulawak. Hal ini dikarenakan sebagian besar dokter yang berpartisipasi dalam riset Registri Jamu menggunakan jamu saintifik dari B2P2TOOT Tawangmangu. Jamu yang sering menjadi bagian dari pengobatan komplementer dispepsia adalah kunyit (Curcuma domestica), jahe (Zingiber officinale), dan temulawak (Curcuma xanthorrhiza). Jenis jamu ini juga menjadi penyusun formula jamu Saintifik B2P2TOOT. Formula jamu saintifik dispepsia terdiri atas kunyit (Curcuma domestica), jahe (Zingiber officinale), jinten hitam (Nigella sativa), dan sembung (Blumea balsamifera). Formula ini aman untuk diberikan tiga kali sehari selama 56 hari dan terbukti tidak mengganggu fungsi hati pasien serta tidak ditemukan efek samping yang bermakna. ${ }^{13}$ Jahe (Zingiber officinale Roscoe) secara empiris digunakan sebagai penguat perut dan efektif untuk masalah pencernaan, kembung, dan mual. Secara farmakologis, tanaman ini memiliki efek sebagai pembasmi radikal bebas, antioksidan, antiulcer, antibakteri, antispasmodik, dan antiinflamasi. Penelitian pengaruh jahe terhadap motilitas lambung menunjukkan bahwa jahe dapat meningkatkan kecepatan motilitas lambung dan pengosongan lambung lebih dari plasebo. Efek ini berpotensi bermanfaat dalam kelompok pasien dengan gejala dispepsia. ${ }^{15}$ Formula herbal untuk mengatasi dispepsia juga digunakan di negara lain seperti Jepang yang menggunakan obat herbal kampo Rikkunshito. Rikkunshito terdiri dari 8 herbal yaitu: Glycyrrhizae radix, Zingiberis rhizoma, A. lanceae rhizoma, Zizyphi fructus, A. nobilis pericarpium, Ginseng radix, Pinelliae tuber, and Hoelen. Studi menunjukkan bahwa Rikkunshito meningkatkan akomodasi lambung dan mempercepat waktu pengosongan lambung. ${ }^{16}$ Penggunaan jamu untuk mengatasi masalah kesehatan masih mendapat tempat tersendiri pada masyarakat Indonesia. Berdasarkan penelitian yang menganalisis perilaku konsumen yang membeli jamu saintifik menyatakan bahwa responden masih mencari pengobatan tradisional (jamu saintifik) bila sakit dengan alasan jamu tidak ada efek samping dan hal utama yang dipertimbangkan adalah manfaat dari jamu. Responden merasa puas setelah menggunakan jamu dan mempunyai loyalitas cukup tinggi terhadap jamu. ${ }^{17}$

Selain jamu terdapat yankestrad lain yang digunakan oleh pasien dalam mengatasi keluhan dispepsia seperti akupunktur, akupresur, pijat, dan bekam. Akupunktur pada titik Zusanli, Neiguan dan Neiting serta kombinasi dengan kunyit2 kapsul @ $500 \mathrm{mg}$ sebanyak 2 kali sehari selama 28 hari dapat memperbaiki kondisi gastritis. ${ }^{18}$ Akupunktur pada titik PC6 dan ST36 dapat memperbaiki motilitas lambung pada penderita dispepsia fungsional dengan gangguan pengosongan lambung. Selain itu, keluhan dispepsia fungsional seperti nyeri ulu hati, mual, muntah, anoreksia, rasa terbakar, dan kembung ditemukan berkurang setelah terapi akupunktur. ${ }^{19}$ Sebuah meta-analisis dari 24 uji klinik (Randomizied Clinical Trial) mengevaluasi kemanjuran akupunktur untuk pengobatan dispepsia fungsional melaporkan perbaikan gejala dan kualitas hidup pasien. ${ }^{10}$ Adanya ketidakpuasan pasien ganggan gastrointestinal yang menjalani pengobatan konvensional, menjadikan mereka beralih pada pengobatan komplementer yang menjadi pilihan yang cukup menarik bagi pasien. Perawatan gangguan gastrointestinal secara komplementer alternatif memberikan hasil yang lebih baik terutama dari segi kualitas hidup pasien. ${ }^{20}$

\section{Kesimpulan}

Kualitas hidup umum maupun khusus pada pasien dengan keluhan dispepsia yang diberi perawatan dengan jamu oleh dokter praktik jamu cenderung rmeningkat seiring dengan bertambahnya frekuensi waktu kunjungan. 


\section{Saran}

Perlu dilakukan analisis terhadap data jamu yang dapat meningkatkan kualitas hidup pasien dispepsia.

\section{Keterbatasan Penelitian}

Registri jamu merupakan riset pengembangan sehingga ada beberapa variabel yang tidak sama setiap tahunnya. Hal ini menyebabkan keterbatasan dalam pengolahan data.

\section{Kontribusi Penulis}

TW dan DD melakukan proses pengumpulan data. NP dan DD melakukan analisis statistik. TW Menyiapkan referensi dan menuliskan draft artikel. DD dan NP menambahkan pada bagian pembahasan.

\section{Ucapan Terima Kasih}

Ucapan terima kasih disampaikan kepada Kepala Badan Litbangkes, Kepala Pusat Teknologi Terapan Kesehatan dan Epidemiologi Klinik dan Kepala Puslitbang Sumber Daya dan Pelayanaan Kesehatan atas dukungan dalam pengembangan Registri Jamu.

\section{Daftar Rujukan}

1. Purnamasari L. Faktor risiko, klasifikasi, dan terapi sindrom dispepsia. Cermin Dunia Kedokteran. 2017;44(12):870-3.

2. Muya Y, Murni AW, Herman RB. Karakteristik penderita dispepsia fungsional yang mengalami kekambuhan di Bagian Ilmu Penyakit Dalam RSUP Dr. M. Djamil Padang, Sumatera Barat Tahun 2011. Jurnal Kesehatan Andalas. 2015;4(2):490-6. doi:10.25077/jka.v4i2.279

3. Delima, Widowati L, Siswoyo H, Sampurno OD, Halim S. The Pattern of Herbal Medicine Prescribed by Medical Doctor for Ten Health Problems in Several Cities of Indonesia (Analysis of Jamu Registry 2016 and 2018 Database). 4th Int Symp Heal Res (ISHR 2019) The Adv Heal Sci Res. 2020;22(Ishr 2019):6259. doi:10.2991/ahsr.k.200215.122

4. Hantoro IF, Syam AF, Mudjaddid E, Setiati S, Abdullah M. Factors associated with healthrelated quality of life in patients with functional dyspepsia. Health Qual Life Outcome. 2018; 16(1):83. doi:10.1186/s12955-018-0913-z
5. Chiarioni G, Pesce M, Fantin A, Sarnelli G. Complementary and alternative treatment in functional dyspepsia. United European Gastroenterol J. 2018;6(1):5-12. doi:10.1177/ 2050640617724061

6. Aditama TY. Jamu \& Kesehatan. Jakarta: Lembaga Penerbit Balitbangkes (LPB); 2014.

7. Delima. Registri Jamu. Laporan Penelitian. Jakarta: Puslitbang Sumber Daya dan Pelayanan Kesehatan, Balitbangkes, Kemenkes; 2016.

8. Delima. Pencatatan Medik Berbasis Web untuk Pelayanan Jamu/Ramuan Herbal pada Pasien dari 10 Penyakit oleh Dokter Praktik Jamu. Laporan Akhir Penelitian. Jakarta: Puslitbang Sumber Daya dan Pelayanan Kesehatan, Balitbangkes, Kemenkes; 2018.

9. Purnama YHC. Pengaruh bekam terhadap penurunan nyeri pada klien dengan trapezius myalgia pada pekerja angkut di Kecamatan Jelbuk Jember. Indones J Health Sci. 2018; Suppl 1:66-76. doi:10.32528/ijhs.v0i0.1524

10. Sumarni S, Andriani D. Hubungan pola makan dengan kejadian dispepsia. J Keperawatan Fisioter. 2019;2(1):61-6. doi:10.35451/jkf. v2i1.282

11. Piotrowicz G, Stẹpień B, Rydzewska G. Socio-demographic characteristics of patients with diagnosed functional dyspepsia. $\operatorname{Prz}$ Gastroenterol. 2013;8(6):354-65. doi:10.5114/ pg.2013.39918

12. Sugiyarto OP, Probosuseno, Puspitasari I. Perbandingan kualitas hidup pasien dispepsia yang menggunakan lansoprazol dengan injeksi ranitidin. JManajemen dan Pelayanan Farmasi. 2014;4(3):180-4.

13. Triyono A, Astana PRW, TI Pamodyo S. Observasi klinik efek formula jamu dispepsia terhadap fungsi hati. J Trop Pharm Chem. 2016;3(4):246-50. doi:10.25026/jtpc.v3i4.112

14. Siswanto. Pengembangan kesehatan tradisional indonesia: konsep, strategi dan tantangan. Jurnal Penelitian dan Pengembangan Pelayanan Kesehatan. 2017;1(1):17-31. doi:10.22435/ jpppk.v1i1.429

15. Babaeian M, Naseri M, Kamalinejad M, Ghaffari F, Emadi F, Feizi A, et al. Herbal remedies for functional dyspepsia and traditional Iranian medicine perspective. Iran Red Crescent Med J. 
2015;17(11):e20741. doi:10.5812/ircmj.20741

16. Kusunoki H, Haruma K, Hata J, Ishii M, Kamada T, Yamashita $\mathrm{N}$, et al. Efficacy of Rikkunshito, a traditional Japanese medicine (Kampo), in treating functional dyspepsia. Intern Med. 2010;49(20):2195-202. doi: 10.2169/internalmedicine.49.3803

17. Maryani H, Kristiana L, Lestari W. Faktor dalam pengambilan keputusan pembelian jamu saintifik. Buletin Penelitian Sistem Kesehatan. 2016;19(3):200-10. doi:10.22435/ hsr.v19i3.6327.200-210

18. Hidayah B. Penanganan Gastritis Menggunakan Kombinasi Terapi Akupunktur pada Titik
Zusanli (ST36), Neiguan (PC6), Neiting (ST44) dengan Herbal Kunyit (Curcuma domestica Val.). [Tugas Akhir]. Surabaya: Fakultas Vokasi Universitas Airlangga Surabaya. 2017.

19. Yoveline A, Abdullah M, Darmawan G, Mihardja H, Sungkar S. Acupuncture in the management of functional dyspepsia. Indones $J$ Gastroenterol Hepatol Digest Endosc. 2012;13(1):49-55. doi:10.24871/131201249-55

20. Mohiuddin AK, Nasirullah M. Conventional and alternative measures for IBS management. Curr Trends Gastroenterol Hepatol. 2019;2(5):11-5. doi:10.32474/ctgh.2019.02000146 